\title{
Vehicle Fuel Activities Monitoring System Using IoT
}

\author{
Rasheda Khatun ${ }^{\circledR}$, Sabbir Ahmed Antor, Ahsan Ullah, Afzal Hossain \\ Department of Computer Science and Engineering, World University of Bangladesh, Dhaka, Bangladesh \\ Email: rashedakhatun225@gmail.com, sabbirantor@gmail.com, ahsan.ullah@cse.wub.edu.bd, afzal2@cse.wub.edu.bd
}

How to cite this paper: Khatun, R., Antor, S.A., Ullah, A. and Hossain, A. (2019) Vehicle Fuel Activities Monitoring System Using IoT. Advances in Internet of Things, 9, 63-71.

https://doi.org/10.4236/ait.2019.94005

Received: September 9, 2019

Accepted: October 20, 2019

Published: October 23, 2019

Copyright $\odot 2019$ by author(s) and Scientific Research Publishing Inc. This work is licensed under the Creative Commons Attribution International License (CC BY 4.0).

http://creativecommons.org/licenses/by/4.0/

\begin{abstract}
IoT is extensively used in everyday object and its popularity is increasing day by day. In this paper it includes the design and development of an IoT and mobile-based vehicle fuel activities such as real time fuel monitoring and GPS tracking system. The proposed IoT device measures the amount of fuel by using ultrasonic fuel sensor. When the vehicle tank of fuel reaches a certain level, driver gets notification through mobile application and also searches the nearest pump location for reloading fuel. The proposed system used GPS tracking for showing current location of vehicle and finding nearest pump location.
\end{abstract}

\section{Keywords}

Fuel Monitoring, GPS, Ultrasonic Sensor, NodeMCU (ESP8266), Android Application

\section{Introduction}

\section{Research Background}

The internet of things [1], or IoT, is a system of interrelated computing devices, mechanical and digital machines, objects, animals or people that are provided with unique identifiers and the ability to transfer data over a network without requiring human-to-human or human-to-computer interaction [2]. Fuel-management systems are designed to effectively measure and manage the use of fuel within the transportation and construction industries. This information can be then stored in computerized systems and reports generated with data to inform management practices. This enables consumption control, cost analysis and tax accounting for fuel purchases [3]. Modern vehicle tracking systems commonly use GPS technology for locating the vehicle, but other types of automatic vehicle location 
technology can also be used.

As fuel cost is rising constantly, people are facing fuel theft at petrol pumps. In that, vehicle owners do not calculate how much quantity of fuel needs in a day or in a week. Time is important for efficient goods transportation system such as real time tracking and reducing financial fuel loss of vehicles is rapidly increased. This can be overcame by using real time tracking vehicle system, such as a system which monitors current amount of fuel via mobile application. The new driver does not know where is the nearest fuel pumps from his current location. This android application helps to find nearest fuel pumps. A driver can easily target the nearby pump fuel and reach there within a few times. Using this approach, a vehicle owner will help the user to monitor and control all of the vehicles from a remote location.

In the present situation, this project plays a vital role in vehicle activities. Nowadays, real time fuel-filled and fuel consumption in vehicles is not maintained. For this kind of problem, when the driver starts filling fuel in the tank, the ultrasonic sensor gets activated and store data on the mobile application. Some of the drivers can drive without asking his vehicle owner. At that time, the driver used the vehicle for rental or personal use. By utilized the mobile application, the owner can trace all the vehicles in the same period, find very nearest fuel pump from the vehicle location, notify when fuel goes to a certain level.

The proposed vehicle activities monitoring system is reliable, easy to implement and user friendly, which keeps monitoring through the mobile application. Tracking vehicles has always been a problem with transport vehicles or cargo vehicles for big companies dealing. This project is useful for transportation companies. The private car owners also can be benefited from using the project.

\section{Literature Review}

In [4] the author proposed a system for overcoming fraud at petrol-pumps. In an instant, when agent starts filling fuel in vehicle tank the flow sensor gets activated and provides a series of pulses proportional to instantaneous flow rate. The ESP8266 sends the data to the cloud server. User application also locates the user throw GPS. The reviewed paper works with flow sensor for measuring fuel whereas the proposed system works with ultrasonic sensor which can measure fuel from various dimension fuel tanks.

In [5] the author proposed a system for vehicle monitoring and tracking systems using Blynk platform acting as a medium for data transfer and visualization. This system is implemented using Ultrasonic sensor, Gas sensor, IR sensor, Temperature sensor, GPS. The reviewed paper used Blynk for monitoring whereas the proposed system used mobile application for monitoring.

In [6] the author proposed a system to develop a method that provides vehicle tracking, monitoring and alerting System. Alerting system uses GSM or GPRS for sending information. GPS is used to inform the user about exact location of vehicle. The reviewed paper proposed to develop vehicle tracking, monitoring and alerting system whereas the proposed system develop vehicle activities such 
as fuel monitoring, vehicle location tracing, find nearest fuel pump and get alerting notification.

In [7] the author proposed a system to consist of arduino, GPS, GSM, fuel sensor and speed sensor. It provides the outcomes from the interaction between the system devices, which are on the bus, web application and desktop application. The reviewed paper used GSM for sending data whereas the proposed system used NodeMCU (ESP8266) for sending data and it use web application to monitoring the system whereas the proposed system uses a mobile application to monitoring the system.

In [8] the author proposed a system for tracking and positioning of any vehicle by using Global positioning System (GPS) and (GSM) this system is continuously control and monitoring report the status of vehicle which is only possible by the reporting frequency of GPS tracking. It will monitor and track their vehicles for safety concerns with the help of android applications. The reviewed paper works with PIC18F4520 whereas the proposed system works with NodeMCU.

In [9] the author proposed a system to track the vehicle by using GPS and GSM technology. The GPS and a GSM modem with an Arduino MEGA2560 which is attached to the vehicle. The reviewed paper used GSM to send data whereas proposed system use NodeMCU (ESP8266) which has built in WiFi chip to send data in database.

In [10] the author proposed a system which helps the user to exploit the working of multiple processors in parallel. In this system user interface is on another android mobile where the user can track the vehicle on Google map. The reviewed paper works only for vehicle location track whereas the proposed system works for vehicle activities such as fuel monitoring and vehicle location tracking.

In [11] the author proposed a method that provides a solution using Arduino, GPS, GSM and Web-Based Technologies. The reviewed paper used online MYSQL database server to store the information whereas the proposed system used online firebase database to store the information and in the reviewed paper author used web application to monitoring the system whereas the proposed system used mobile application to monitoring the system.

In [12] the author proposed a system to developed android app based vehicle tracking using GPS and GSM. This system mainly focuses on tracking the location of the vehicle on which the device has been installed. The reviewed paper build communication between user and system through GSM and it sends data using GSM whereas the proposed system used NodeMCU (ESP8266) to communicate and sends data to the user.

\section{Methodology}

A methodology is a set of methods, which describe the process of a project or system such as designing, planning, implementation and maintenance. The au- 
thors have completed their project using following methodology (Figure 1).

\section{Design and Development}

\subsection{System Architecture}

System architecture is a conceptual model that defines the structure, behavior and more views of a system (Figure 2). For building up this model, first we need an ultrasonic sensor which measures the level of fuel. Then convert it into volume. It sends the data into firebase through NodeMCU (ESP8266) module as well as the GPS module sends the latitude and longitude of the vehicle. The server views all data in the mobile application and it is a real time monitoring and location tracking system.

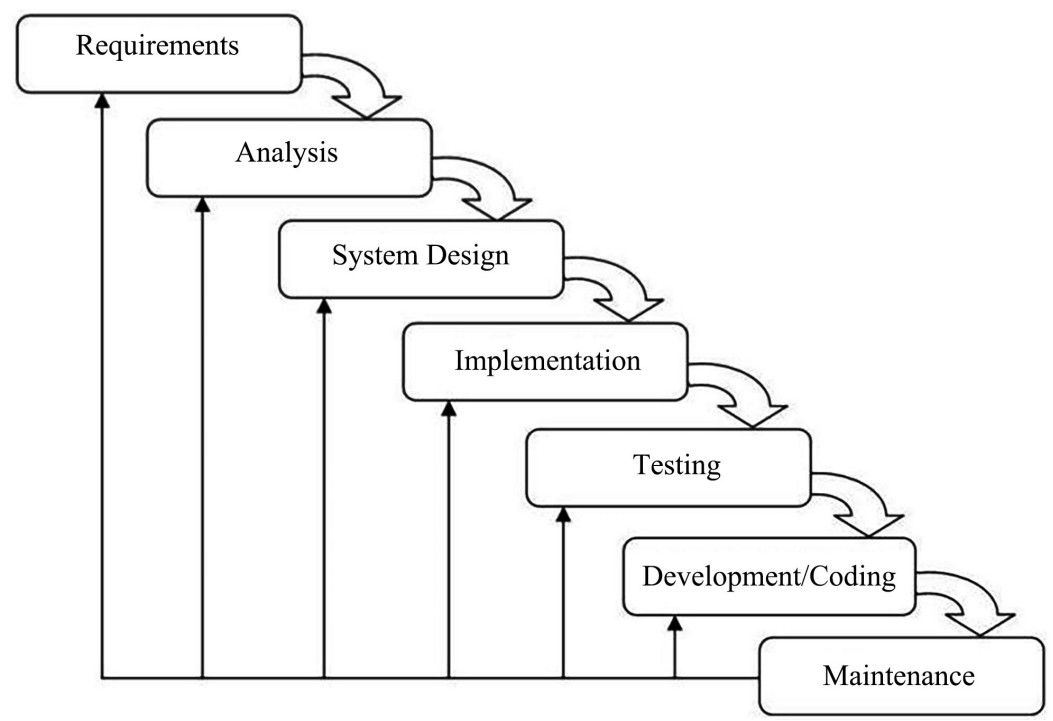

Figure 1. Diagram of proposed methodology.

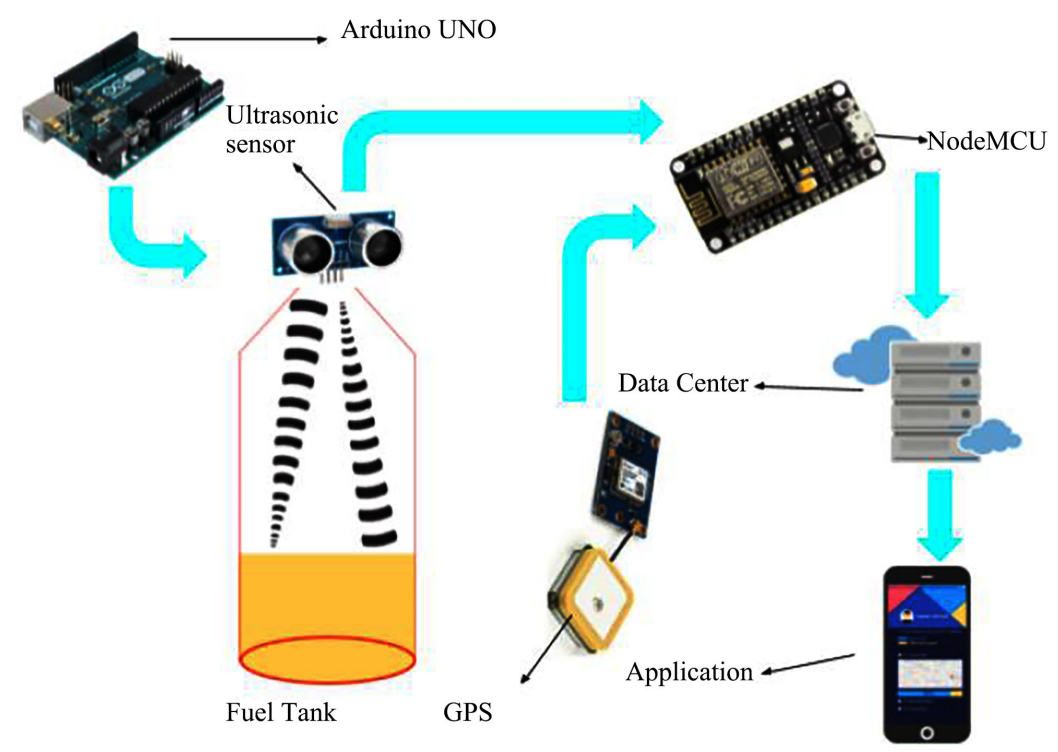

Figure 2. System architecture of proposed system. 


\subsection{Circuit Diagram}

A circuit graph could be a graphical representation of an electrical circuit (Figure 3). A pictorial circuit diagram uses straightforward pictures of components, whereas a schematic chart appears the components and interconnections of the circuit utilizing standardized typical representations.

Ultrasonic sensor mainly comprises of four pins VCC, GND, Echo, Trigger, VCC supply for ultrasonic sensor is usually $5 \mathrm{v}$. VCC is connected with arduino pin $5 \mathrm{v}$, GND pin is connected to the GND pin of arduino, the trig and echo pins are connected to the D7 and D6 pins on the NodeMCU. To generate the ultrasound, it is needed to set the trig on a high state and the generated sound will be received by the echo pin. GPS is connected with NodeMCU. It has four pins VCC, GND, Tx, Rx. The VCC and GND pin is connected with NodeMCU pins 3.3v and GND, Rx and Tx pin is connected with NodeMCU pins D3 and D4.

\subsection{Working Flow Diagram}

A flowchart is a type of diagram that represents an algorithm, workflow or process (Figure 4). Flowchart can also be defined as a diagrammatic representation of an algorithm. The flowchart shows the steps as boxes of various kinds, and their order by connecting the boxes with arrows.

An ultrasonic sensor is placed in the bottom of the fuel tank. It can calculate the distance between the top at the fuel level and the bottom of the fuel tank by using the formula distance $=\left(0.034^{*}\right.$ time $) / 2$. A GPS is placed in the front part of the vehicle and it gives longitude and latitude values. The values of sensor and GPS are collected by NodeMCU as it has inbuilt Wi-Fi module all the data is transferred to the cloud through Wi-Fi and analysis is done in mobile application and notifications are sent according to the conditions.

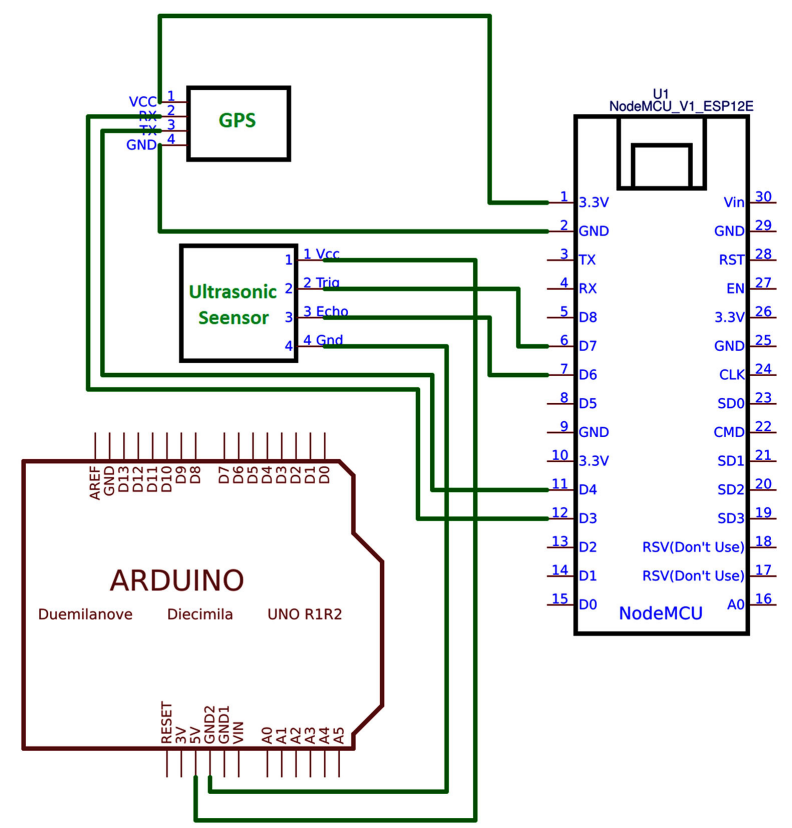

Figure 3. Circuit diagram of proposed IoT device. 


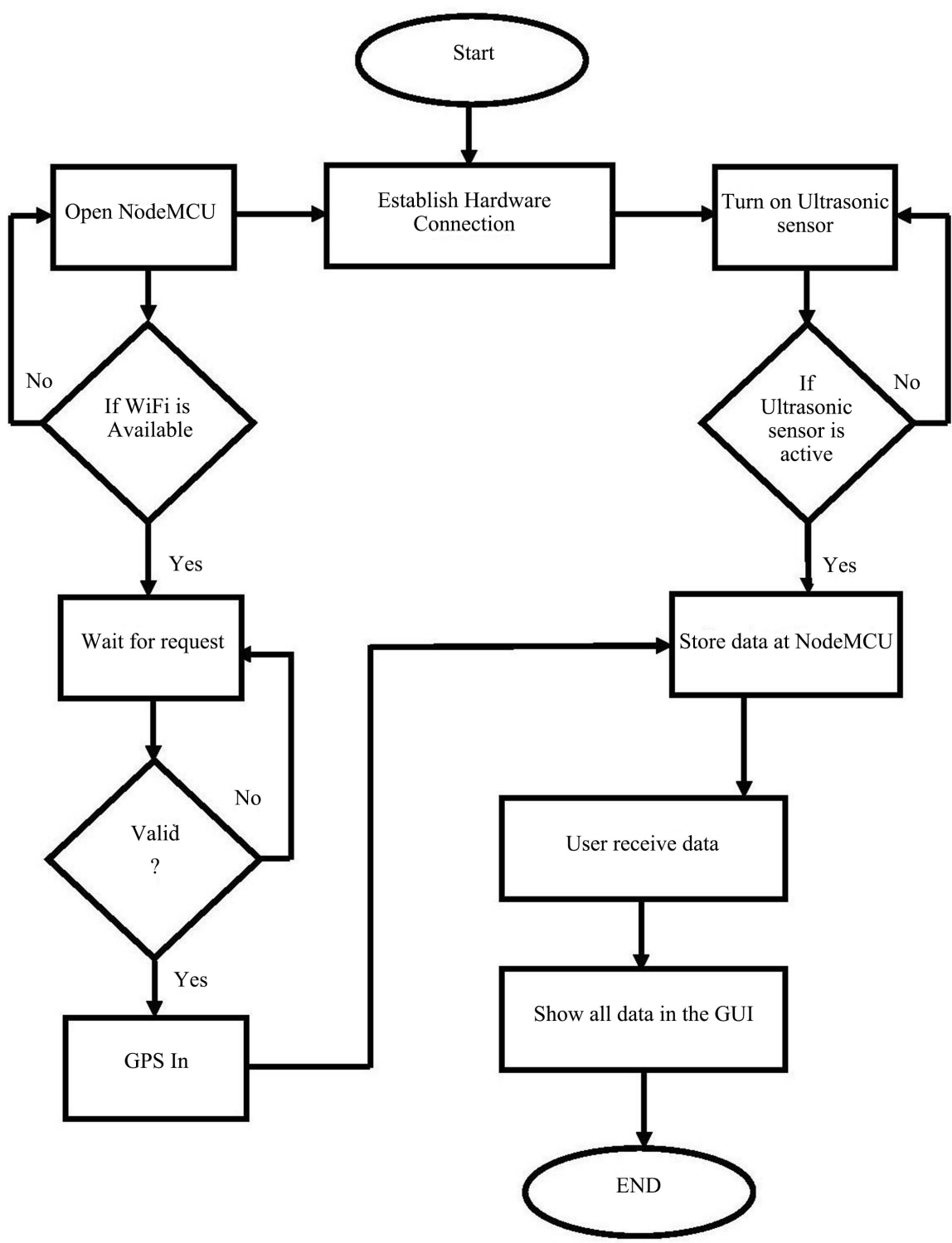

Figure 4. Flow diagram of proposed system.

\subsection{ER-Diagram}

An entity-relationship demonstrate depicts interrelated things of intrigued in a particular space of information (Figure 5). A basic ER model is composed of entity types and specifies relationships that can exist between entities. Using this ER-diagram authors create database in firebase. In this ER-diagram authors use two primary keys which are Device_ID and User_Name.

\section{Project Description}

\subsection{Device Prototype}

In the following, Figure 6 represents one Ultrasonic sensor, GPS, NodeMCU, Arduino. When we generate the power into the system indicator lights are turned on and the system starts to work properly. 


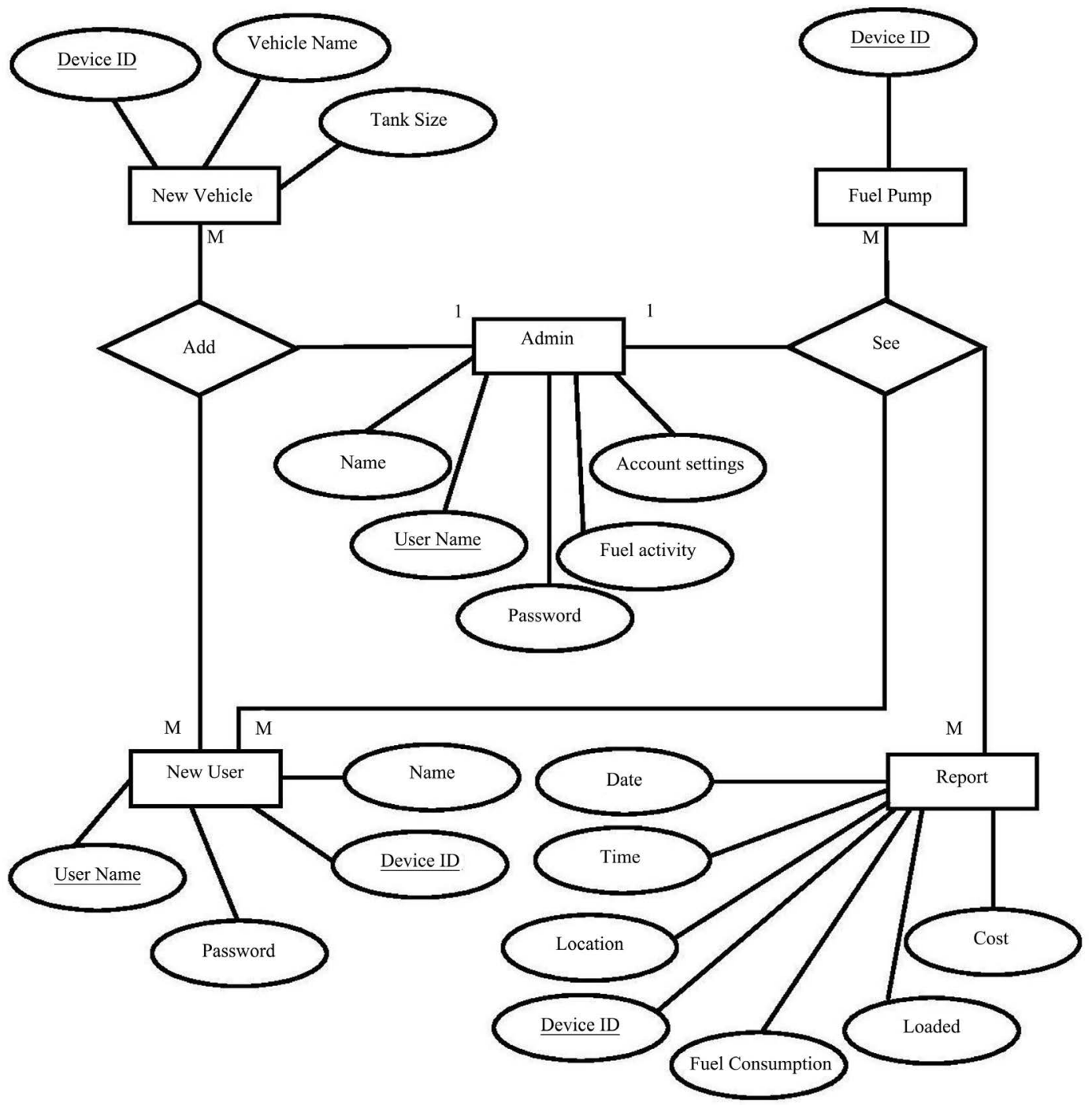

Figure 5. ER-Diagram of proposed system.

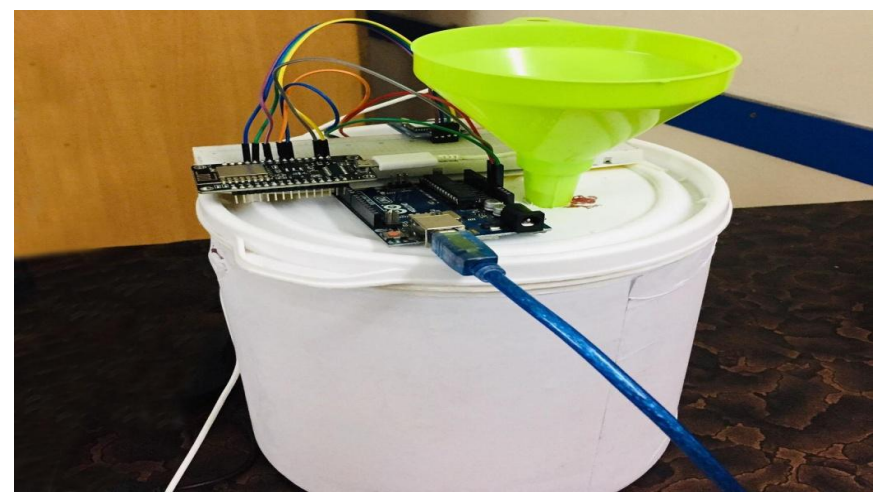

Figure 6. Device prototype.

\subsection{Vehicle Fuel Measurement with Current Location}

In Figure 7, vehicle owner can check real time amount of fuel and trace vehicle location. 


\subsection{Warning Notification for Reloading Fuel from the Nearest Pump}

In this (Figure 8) represents showing nearest pump location and (Figure 9) represents warning notification.

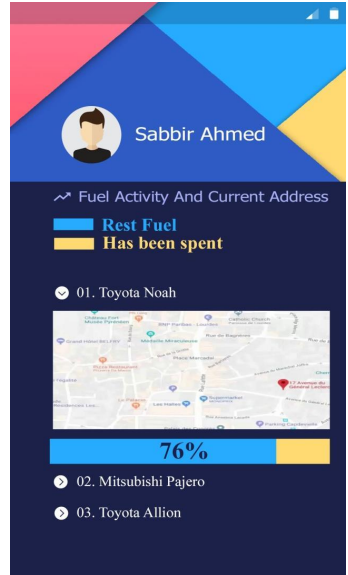

Figure 7. Fuel activity and current address.

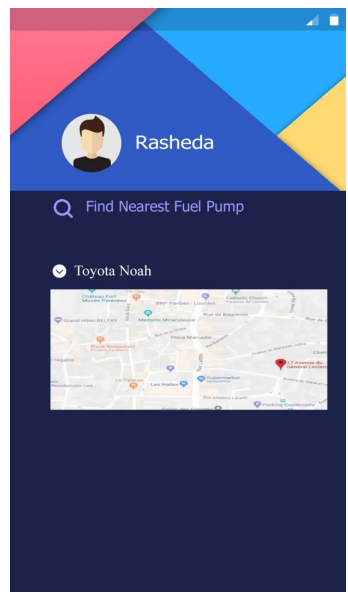

Figure 8. Showing nearest pump location.

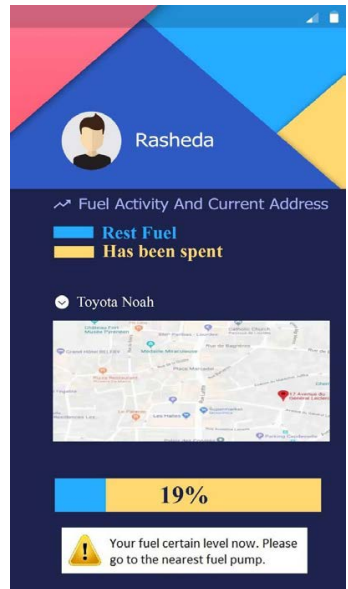

Figure 9. Warning notification. 


\section{Conclusion}

The proposed system will provide an accurate and real-time fuel monitoring system. This is a suitable and practical solution for fuel monitoring and location tracking. Therefore this system can be implemented in every vehicle to avoid facing fuel theft, finding the nearest fuel pump and vehicle location. The authors used a central monitoring system to control all vehicles by using the mobile application.

\section{Conflicts of Interest}

The authors declare no conflicts of interest regarding the publication of this paper.

\section{References}

[1] Definition of IoT-Google Search. https://internetofthingsagenda.techtarget.com/definition/Internet-of-Things-IoT

[2] Describe Fuel Monitoring-Google Search. https://en.m.wikipedia.org/wiki/Fuel-management_systems

[3] Describe Vehicle Activities Monitoring-Google Search. https://en.wikipedia.org/wiki/Vehicle_tracking_system

[4] Chiwhane, S.A., et al. (2017) IOT Based Fuel Monitoring for Future Vehicles. International Journal of Advanced Research in Computer and Communication Engineering, 6, 295-297.

[5] Padmaja, B.V., et al. (2019) IoT Based Implementation of Vehicle Monitoring and Tracking System Using Node MCU. International Journal of Innovative Technology and Exploring Engineering, 8, 446-450.

[6] Dukare, S.S., Patil, D.A. and Rane, K.P. (2015) Vehicle Tracking, Monitoring and Alerting System: A Review. International Journal of Computer Applications, 119, 39-44. https://doi.org/10.5120/21107-3835

[7] Gullipalli, S., Karri, Y. and Kota, S. (2018) GPS Live Tracking of Buses and Fuel Monitoring System Using Arduino. International Journal for Research in Applied Science \& Engineering Technology, 6, 2278-2285. https://doi.org/10.22214/ijraset.2018.3362

[8] Vanmore, S.V., et al. (2017) Smart Vehicle Tracking Using GPS. International Research Journal of Engineering and Technology, 4, .

[9] Alshamisi, H. and Këpuska, V. (2017) Real Time GPS Vehicle Tracking System. International Journal of Advanced Research in Electronics and Communication Engineering, 6,.

[10] Rohitaksha, K., Madhu, C.G., Nalini, B.G. and Nirupama, C.V. (2014) Android Application for Vehicle Theft Prevention and Tracking System. International Journal of Computer Science and Information Technologies, 5, 2014.

[11] Khin, M.M. and Oo, N.N. (2018) Real-Time Vehicle Tracking System Using Arduino, GPS, GSM and Web-Based Technologies. International Journal of Science and Engineering Applications, 7, 433-436. https://doi.org/10.7753/IJSEA0711.1006

[12] Saini, J., Agarwal, M., Gupta, A. and Manjula, R. (2017) Android App Based Vehicle Tracking Using GPS and GSM. International Journal of Scientific \& Technology Research, 6, 53-58. 